\title{
LEVADURAS AISLADAS DE DIVERSOS TIPOS DE ALIMENTOS
}

Oliane Maria Correia Magalhaes

Lusinete Aciole de Queiroz

Centro de Ciencias Biológicas, Universidade Federal de Pernambuco, Av. Prof. Artur de Sá, s/n, Cidade Universitaria, CEP 50.740, Recife

PE - BRASIL.

Palabras clave: Levaduras, alimentos, Candida, Debaryomyces, Pichia.

Key words: Yeasts,foods, Candida, Debaryomyces, Pichia.

\section{RESUMEN}

Se investigó la presencia de levaduras en 4 grupos de alimentos constituidos por frutas frescas, frutas procesadas, derivados de leche y cames industrializadas, aislándose 392 muestras de levaduras pertenecientes a 11 especies de Candida, 6 de Debaryonyces y 3 de Pichia. Los géneros Candida y Debayonyces se detectaron en los 4 gnupos de alimentos; Pichia no se detectó en cames industrializadas.

\section{RESUMO}

De 4 grupos de alimentos constituidos de frutas frescas, frutas processadas, derivados de leite $e$ carmes industrializadas, foram isoladas 392 amostras de leveduras pertencentes a 11 espécies de Candida, 6 de Debayomyces e 3 de Pichia. Os géneros Candida $e$ Debayomyces, ocorreram nos 4 grupos de alimentos; Pichia nao ocorreu no grupo de cames industrializadas.

\section{INTRODUCCION}

Como otros organismos, los hongos participan en procesos importantes reflejados a través de las relaciones directas o indirectas con el hombre (Gray 1959, Moss 1987). Tanto los hongos filamentosos como las levaduras, desempeñan un papel relevante en las industrias de alimentos, cuando son usados directamente o como suplemento alimenticio; así como también en los procesos de biodegradación y biodeterioro. Vale la pena señalar que según el sustrato y el producto final, muchas veces una especie de hongo puede actuar tanto en procesos de biodegradación como en los de biodeterioro (Cook 1958, Gray 1959 y Rose 1987).

\section{SUMMARY}

\section{[Yeast isolated from different type of foods.]}

The presence of yeast was investigated in 4 groups of food: fresh fruits, processed fruit, milk derivates and industrialized meat, isolating 392 yeasts samples belonging to 11 species of the genus Candida, 6 Debaryomyces, and 3 Pichia. The genera Candida and Debaryomyces was detected in the 4 four groups of food; Pichia was not detected in industrialized meat.

Entre otras levaduras, Saccharomyces cerevisiae, S. carlsbergensis, $\mathbf{S}$. fragilis, Candida utilis, C. tropicalis y Lipomyces kononenkoae son usadas como suplemento alimenticio, debido a su alto valor proteico, así como la presencia de vitaminas del complejo "B" en sus respectivas células (Cook 1958, Gray 1959, Rose 1987 y Horn et al.1988).

Varias levaduras son conocidas a través de procesos de biodegradación en la industria de alimentos, destacándose varias especies de Saccharomyces, Hansenula, Pichia y otros géneros utilizados en la fabricación de pan, cerveza, vino, sake, whisky, ron, vodka y otros licores; también pueden ser mencionadas las especies de Candida, Brettanomyces y Endomycopsis, usadas respectivamente en la fer- 
mentación del cacao, producción de vinagre y grasas (Cook 1958, Jay 1970, Frazier 1976 y Rose 1987).

Además de su particpación en los procesos de biodegradación, las levaduras actúan en los de biodeterioro de alimentos naturales e industrializados; los géneros Candida, Brettanomyces, Rhodotorula, Debaryomyces, Kluyveromyces, Pichia, Trichosporon, Kloeckera, Saccharomyces, Zygosaccharomyces entre otros, han sido aislados de alimentos naturales, tales como frutas frescas o secas, jugos, miel, leche y otros, así como de alimentos industrializados en forma de jugos, dulces, chocolates, melaza, vinos, cervezas, derivados de jugo de carne (Cook 1958, Jay 1970, Frazier 1976, Staib et al. 1980, Iwo 1982, Wiskiewski et al. 1988).

Entre los trabajos publicados en los áltimos años, sobre aislamiento de levaduras, pueden ser mencionados algunos, donde especies de Candida, Debaryomyces, Kluyveromyces, Pichia, Rhodotorula y Saccharomyces, fueron aisladas de derivados de leche por Suriyarachchi \& Fleet (1981). Ivo (1982), aisló desde frutas varios géneros, entre ellos, Candida y Dekkera . Saccharomyces bailii var. bailii fue aislado por Grillot et al. (1982) y por Buhagiar et al. (1983), así como Saccharomyces cerevisiae por Parish \& Carrol (1987) y Debaryomyces hansenii, por Siewski et al. (1988).

Lo expuesto indica que en Brasil la carencia de trabajos referentes al aislamiento de levaduras contaminantes de alimentos, justifica este trabajo, cuyo objetivo es: aislar e identificar levaduras desde estos sustratos, hacer un análisis cuali-cuantitativo de las levaduras presentes y verificar las posibles implicaciones en función de los resultados.

\section{MATERIAL Y METODOS}

Se analizaron 4 grupos de alimentos aparentemente inalterados: 1).-Frutas frescas: mangaba, pitanga; 2).- Frutas procesadas como, passa de ameixa, aceituna negra en conserva; 3).- Derivados de leche: queso prato, mantequilla; 4).- Carnes industrializadas como, mortadela y jamón cocido.

\section{Medios de cultivo empleados}

Medios para aislamiento de levaduras: Agar Sabouraud y Agar Malta, ambos adicionados de $0,5 \%$ de extracto de levadura (YE) y de $50 \mathrm{mg}$ de cloranfenicol/litro y $\mathrm{pH}$ final 5,5.

Medios para identificación: preconizados por Lodder (1970) y Kreger-van Rij (1984).

\section{METODOS}

\section{Aislamiento de levaduras}

Desinfecciòn: Las frutas frescas y procesadas fueron desinfectadas superficialmente por immersión durante 5 minutos en soluciòn acuosa de formol al 5\% y lavadas 3 veces consecutivas, durante 15,10 y 5 minutos en agua estéril.

Para la preparación de las suspensiones y diluciones respectivas fue utilizada la técnica de Warcup (1950) modificada (método de diluciones): $10 \mathrm{~g}$. de alimento + q.s.p. $100 \mathrm{ml}$ de agua destilada estéril $(\mathrm{ADE})=$ suspensión $1 / 10 ; 1 \mathrm{ml}$. de suspensión $1 / 10$ + q.s.p. $10 \mathrm{ml}$. de $\mathrm{ADE}=$ suspensión de $1 / 100 ; 1 \mathrm{ml}$. de suspensión de $1 / 100+$ q.s.p. $10 \mathrm{ml}$. de $\mathrm{ADE}=$ suspensión de 1/1000.

Después de ser asépticamente pesados los alimentos en una balanza Becker, estos fueron adicionados de $5 \mathrm{ml}$. de ADE y macerados con varilla de vidrio estéril; agregando gradualmente $\mathrm{ADE}$, hasta completar el volumen de $100 \mathrm{ml}$, correspondiendo a la suspensión 1/10. En tubos de ensayo estériles fueron preparadas las suspensiones de, $1 / 100$ y $1 /$ 1000. El examen directo reveló la presencia de levaduras en 3 suspensiones. Debido a la gran cantidad de células de levaduras en las 3 suspensiones, consecuentemente por cuestiones prácticas de aislamiento, la suspensión de $1 / 1000$, fue sembrada en triplicado. Con pipeta graduada de $1 \mathrm{ml}$, fue sembrado $0,2 \mathrm{ml}$ de la suspensión en una superficie de los medios contenídos en las placas. Una suspensión fue esparcida del centro hacia el borde del medio, con una misma pipeta, en movimientos diametralmente paralelos y siendo las placas concomitantemente giradas en $360^{\circ}$ para proporcionar una distribución uniforme. Las placas fueron dejadas a temperatura ambiente (T.A) entre 27 y $30^{\circ} \mathrm{C}$.

\section{Identificación y Clasificación}

La identificación de las levaduras se basó en las técnicas preconizadas en las monografías de Lodder 
(1970) y Kreger-van Rij (1984), Barnett et al. (1986).

Después de clasificadas, las levaduras fueron depositadas en la micoteca URM, del Depto de Micología, CCB, UFPE, Recife, Brasil.

\section{RESULTADOS Y DISCUSION}

De los 4 grupos de alimentos estudiados, fueron aisladas 392 muestras de levaduras, especialmente de los géneros Candida, Debaryomyces y Pichia; este último no fue aislado del grupo de carnes (Tabla 1; Figura 1).

El género Candida fue el más representativo, seguido de Debaryomyces y Pichia (Tabla 1: Figura 1). Estos géneros entre otros, son los más comunmente aislados de los alimentos (Jay 1970, Frazier 1976, Ivo 1982 y Wiskiewsk et al 1988). La prevalencia del género Candida sobre los otros,también ha sido observada por otros investigadores (Suryarachchi \& Fleet 1981, Ivo 1982), entre otros.

El género Candida no se aisló en pitanga ni en mantequilla, habiéndose detectado con menor frecuencia en mangaba, passa de ameixa, jamón cocido, mortadela, queso prato y aceitunas negras en conserva (Tabla 1). De este género fueron aisladas 249 muestras pertenecientes a 11 especies, destacándose Candida haemulonii como la más frecuente, seguida por C. apis, C. diddensii y C. famata, (Tabla 1). C. apis fue aislada de passa de ameixa y de mortadela; $C$. bombícola esacasamente de mortadela; $C$. diddensii de mangaba, passa de ameixa y de mortadela; $\mathbf{C}$. famata de queso prato y jamón cocido; $\mathbf{C}$. glaebosa y C. haemulonii fueron aisladas de jamón y de mangaba respectivamente; C. marítima, en queso prato y jamón cocido; $\mathbf{C}$. valida, $\mathrm{C}$. vini, Candida sp. 1 y Candida sp. 2 se desarro-llaron respectivamente en aceituna negra en conserva, jamón cocido, mangaba y passa de ameixa (Tabla 1). Candida sp. 1 y Candida sp. 2, no pudieron clasificarse. Segín Lodder (1970), Kreger-van Rij (1984) y Barnett et al. (1986). las restantes especies han sido aisladas, respectivamente de: abejas y hormigas, miel de abejas, caña de azúcar y azúcar húmeda, aire, en el hombre, pescado congelado, suelo y agua, de agua de mar, larvas de Rhyphenes maibi, vino, vino, cerveza y en fábricas de productos lácteos.

El género Debaryomyces no se desarrolló en mangaba, aceituna negra en conserva y mortadela, y por orden decreciente de frecuencia, en jamón cocido, pitanga y mantequilla, queso prato y passa de ameixa (Tabla 1). De este género fueron aisladas 80 muestras pertenecientes a 6 especies, siendo Debaryomyces hansenii y D. pseudopolymorphus, los más representativos (Tabla 1). D. hansenii fue aislada de queso prato y jamón cocido; D. polymorphus y $D$. pseudopolymorphus, respectivamente de pitanga y de mantequilla; Debaryomyces sp. 1 de passa de ameixa; Debaryomyces sp. 2 y Debaryomyces sp. 3, de pitanga. Según Lodder (1970), Kreger-van Rij (1984) y Barnett et al. (1986), las 3 especies clasificadas, han sido aisladas de leche, queso, frambuesa, jugo de uva, vino, cerveza, salchicha, salame, tabaco, setas, suelo, aire, puré de tomate, material clínico, musgo, hormiguero y líquidos usado en curtiembre.

El género Pichia fue aislado con mayor frecuencia en mangaba, decreciendo en passa de ameixa, aceituna negra en conserva y queso prato (Tabla 1), no ocurriendo así en pitanga, mantequilla, mortadela y jamón cocido. De este género fueron aisladas 63 muestras pertenecientes a 3 especies: P. membranaefaciens, como la más frecuente, seguida por P. carsoni y P. guillermondii (Tabla 1) . P. membranaefaciens fue aislada de mangaba, passa de ameixa y aceituna negra en conserva; $\mathbf{P}$. carsoni y $\mathbf{P}$. guillermondii, fueron aisladas respectivamente de queso prato y de passsa de ameixa. Lodder (1970), Kreger-van Rij (1984) y Barnett et al. (1986) citan el aislamiento de estas especies, respectivamente de vino, uva, bebidas suaves, frutas, yogurt, pepino en conserva, hombre y otros animales, pelo de caballo, insectos y heces humanas, higos, suelo, flores, cerveza, leche, jugos de frutas.

La revisión oasada en los últimos 10 años, indica que la literatura disponible es escasa de trabajos detallados y actualizados, imposibilitando, por consiguiente una discusión con nuestros resultados. Por otro lado, los datos contenidos en Jay (1970) y Frazier (1976), sugieren que ios alimentos analizados (aparentemente inalterados) en este trabajo, y el elevado número de levaduras aisladas, se consideran como contaminantes, pudiendo participar tanto en procesos de biodegradación como de biodeterioró, lo que podría inutilizar en el tiempo el consumo de los alimentos.

Con respecto a la frecuencia del aislamiento de las levaduras, el mayor fue en mangaba, seguida 


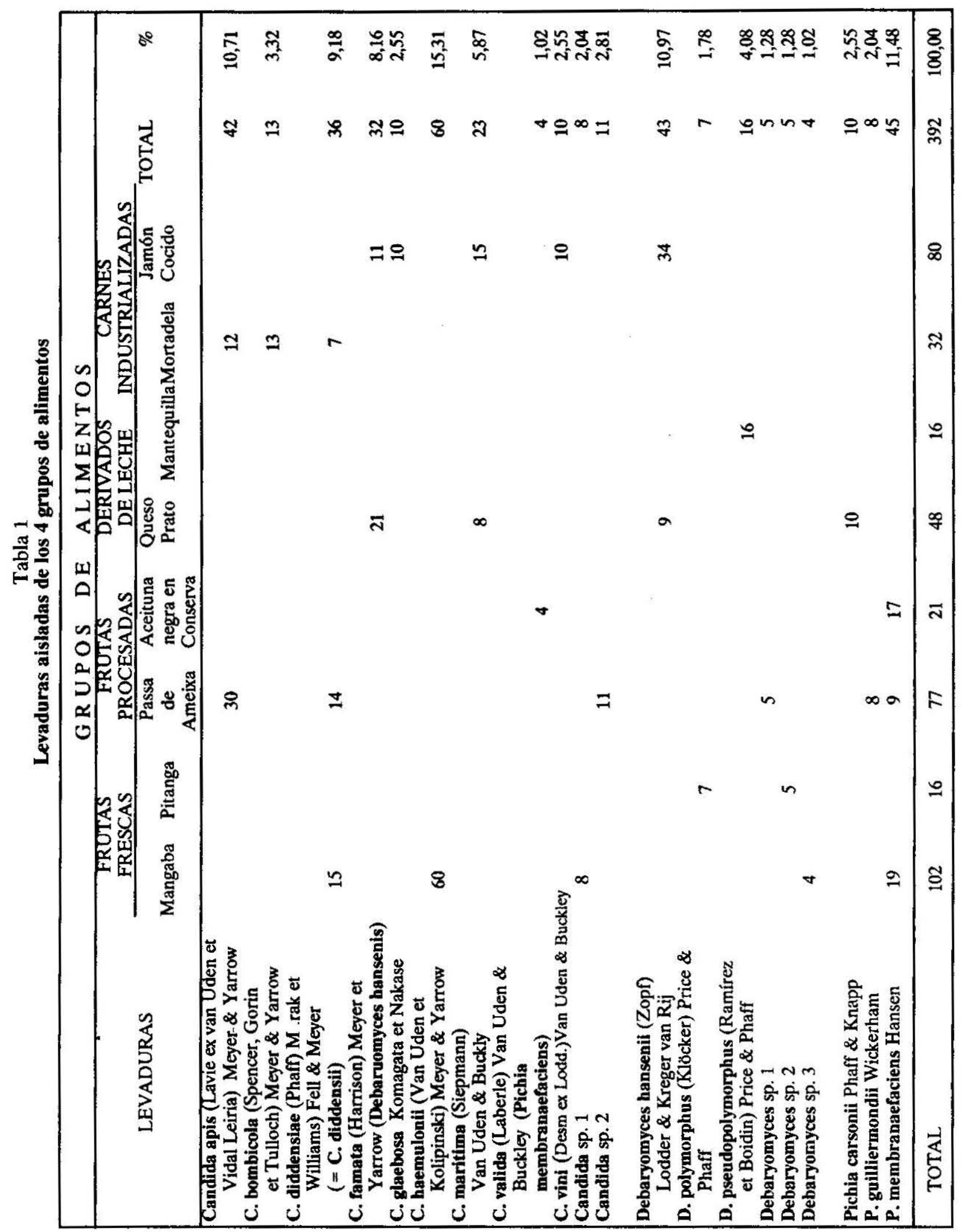


de jamón cocido, passa de ameixa, queso prato, mortadela, aceituna negra en conserva, pitanga y mantequilla (Tabla 1; Fig 1).

\section{CONCLUSIONES}

Todos los alimentos estudiados presentaban levaduras; Plchia no se detectó en el grupo de carnes industrializadas y en general las especies presentes en un grupo de alimento no se repiten en los otros. Candida fue el género más frecuente y $\mathrm{C}$. haemulonii, la especie dominante. La mayor frecuencia de aislamiento de levaduras fue en mangaba y la menor en en mantequilla y pitanga.

Figura 1

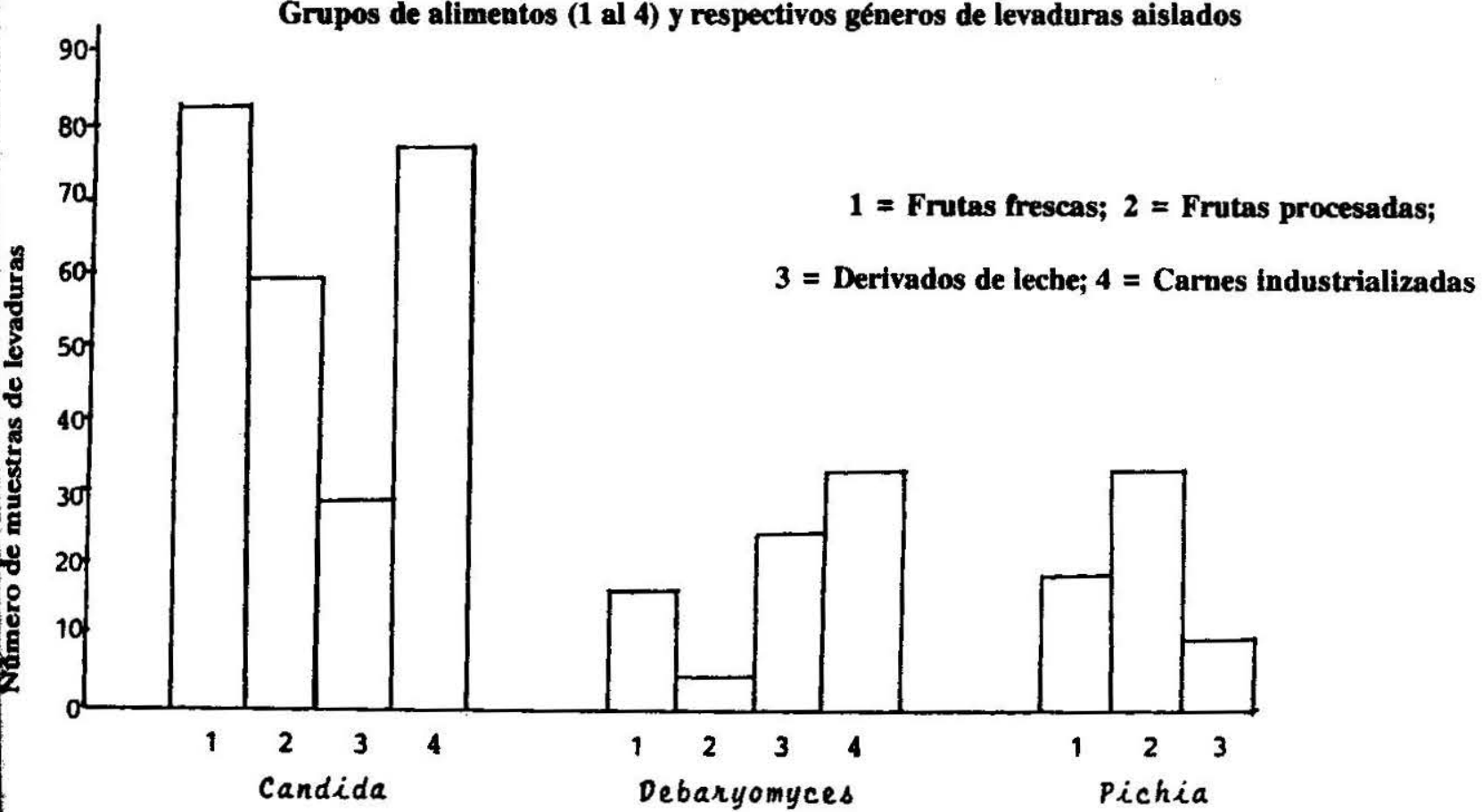

Agradecimientos

A la Prof. Débora Maria Massa Lima.por sus útiles comentarios y enseñanzas.

\section{REFERENCIAS}

Barnett, J.A, Payne, R.W. \& Yarrow, D. (1986). Yeasts: characteristics and identification. New York, Cambridge University Press,

Buhagiar, R.W.M, Yarrow, O. \& Barnett, JA. (1983). Two new yeasts. Gen. Microbiol., 129 : 3149-3156.

Cook, A.H. (1958).The chemistry and biology of yeast. N.York.

Frazier, w.C. (1976). Microbiología de los alimentos. $2^{2} \mathrm{ed}$. Zaragoza, Acribia.
Gray, W. (1959). The relation of fungi to human affairs. Holt Rinehart and Winston, N.York

Grillot, R., Chooteau, J. , Guy,P., Saez, H. \& Ambroise, P.T. (1982). The yeasts in fruit syrups: the value of monitoring and identifying them in a industrial production line. Bull. Soc. Fr. Mycol. Med., 11 : 9-14.

Horn, C.H., Du Preez, J.C. \& Latergan, P.M. (1988). Protein enrichment of banana plant wastes by yeast cultivation. J. Appl. Bacteriol, 24 : 127-136. 
Ivo, M.I. (1982). Leveduras do abacaxi. Sâo Paulo, (Tese Mestrado) Escola Paulista de Medicina.

Jay, J.N. (1970). Modern food microbiology. New York, van Nostrand Reinbold.

Kreger- Van Rij N.J.W. (1984). The yeast: a taxonomic study. $3^{a}$ ed. Elsevier Sci. Publi. Amsterdam.

Lodder, J. (1970). The yeast: a taxonomic study. Oxford, North Holland Publishing Company.

Moss, M.O. (1987) Fungal biotechnology roundup. The mycolo gist, $1: 50$

Parish, M. E. \& Carrol, D.E.(1987). Fermentation characteristics of Saccharomyces cerevisiae isolates from Vitis rotundifolia grapes and musts. Am. J. Enol. Vitic., 38 : 45-48.
Rose, A.H. \& Harrison, J.S. (1987). The yeast: biology of yeasts. Academic Press.

Suriyarachchi, V.R. \& Fleet, G. H. (1981). Ocurrence and growth of yeasts in yogurt. Applied and Environmental Microbiology, 42 : 574-579.

Staib, F, Mishra, S.K, Tompak, B., Grosse, G., Abel, T, Blisse, A, Folkens, V. \& Froehlich, B.(1980). Pathogenic yeast like fungi in meat products. Zentralbl. Infektion Skr. Parasital, 248: $422-429$.

Warcup, J.H. (1950). The soil plate method for isolation on fungi from soil, Nature $166: 116-117$

Wiksiewski, M., Wilson, C. \& Chalutz, E. (1988). Variability in biocontrol of fruit rots among isolates of the yeast Debaryomyces hansenii. Phytopathology, $78: 1592$. 